\title{
Simulation of Vibration Propagated by Rolling Element Bearings in Mechanical Gearbox
}

\author{
Cao Vu TRAN ${ }^{1}$, Jan FURCH ${ }^{2}$, Xuan Phong CU ${ }^{3}$ \\ ${ }^{1}$ Department of Combat and Special Vehicle, Faculty of Military technology, University of Defence in Brno, Address: \\ Kounicova 65, 66210, Brno, Czech Republic \\ ${ }^{2}$ Department of Combat and Special Vehicle, Faculty of Military technology, University of Defence in Brno, Address: \\ Kounicova 65, 66210, Brno, Czech Republic \\ ${ }^{3}$ Faculty of Vehicle and Energy engineering, Le Quy Don Technical University, Address: Hoang Quoc Viet 236, \\ 100000, Hanoi, Vietnam
}

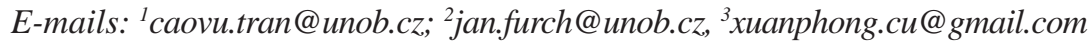

\begin{abstract}
Rolling element bearings are fundamental component parts to be used in rotational mechanical system. During the operation, vibration signals are generated and these signals are related to the technical condition of rotating machinery. The aim of this paper is simulated the vibration signal that propagated by rolling element bearings in mechanical gearbox. The gearbox dynamic model that combined gearbox components, such as, shafts, involute gears, rolling element bearings is developed. The localized fault is created on the inner race of bearing. The model is simulated using multi-body dynamics solution, after that results are analyzed in waveform and spectral in order to assess the behavior of gearbox.
\end{abstract}

KEY WORDS: multi-body dynamics model, localized faults, bearing defect frequencies, vibration analysis

\section{Introduction}

The gearbox is important part of transmission system that plays a role to transfer the torque from the engine to wheels at different ratios. The gearbox consists of complexed components, such as, gears, shafts, bearings and gearbox cases. When mechanisms operate within the gearbox, contact forces generate gear noise and vibration signal in the environment. Contact forces could be induced by gears, bearings, or the interaction with each other. The vibration signal is corresponded with the technical condition and it can be used as a condition monitoring tool to detect and diagnosis gearbox failures. The study about the behavior of gearbox using vibration signal is called vibration diagnostics. The objective of vibrodiagnostics is to recognize an "unhealthy" condition in sufficient time to take into the condition based maintenance before significant defects arise. Vibration monitoring is used at many researches to predict needs for condition-based maintenance. Over the past few years, experiments have been used widely for investigating and diagnostics gearbox failures, such as, the gear tooth damages (pitting, wear, plastic flow, breakage), bearing defects (macro pitting, denting, fretting corrosion, scuffing), and mechanical looseness (misalignment, unbalance) [1]. Among these components, bearings have to work under high load rates and speed, therefore, they are major parts that are sensitive with faults and failures in mechanical system. Base on the research, faults statistics are from bearings (occupies $41 \%$ ), stators ( $37 \%$ ), rotor (10\%), and other $12 \%$ in the electrical motor [2]. Another good example demonstrates that, the faults of 257 damaged gearboxes were from bearings (70 \%), gears (26\%), and others $(4 \%)$ [3]. There are number of vibration signal processing techniques for bearing condition monitoring. Depend on the categories of faults, these techniques could be used, for example, analysis vibration signal in the time domain, in the frequency domain, and time-frequency domain. The analytical model with localized defects on outer race, inner race or on one of rolling elements under radial and axial loads was investigated and analyzed to predict vibration frequencies of rolling bearings [4]. Bearing boxes were investigated to assess the technical condition when the faults located outer ring and the influence of rolling bearing life on the lubricant [5]. The experiment could be used effectively to assess the gearbox behavior. However, it requires the knowledge of experts, the long-term testing procedure, and high investment cost.

To overcome those disadvantages, besides the development of computer technology, the simulation method has been used widely to analyze the mechanical system. The multi-body dynamic solution is the most effective method for vibration analysis. The full dynamic model of ball bearing is developed as consider an effect of the elasticity of the outer ring, a comparison with a rigid body formulation [6]. The dynamic model of a deep groove ball bearing with six degrees

\footnotetext{
${ }^{1}$ Corresponding author.

E-mail address: caovu.tran@unob.cz
} 
of freedom is developed and simulated based on the non-linear Hertzian contact deformation and elastohydrodynamic fluid film. Localized defects, such as inner and outer ring defects, that taken into consideration in the model generated vibration at bearing defect frequencies [7]. The multibody dynamic model is investigated the vibration signal when the misalignment of bearing induced an increase of signal in passenger off-road military vehicle gearbox [8].

The aim of this paper is to develop the mathematical model of dynamic analysis of gearbox. The localized fault is created on the inner race of bearing to investigate an increase of vibration signal when the failure occurs.

\section{Dynamic Model of Gearbox}

The mechanical gearbox is a complex system that composed of different components. Vibration signal can be resulted from gear mesh, bearings, shaft, or the interaction among these parts. It is difficult to described the full mathematical models in gearbox dynamic. An accurate model can be presented not only the actual physical system, but also the essential dynamic characteristics of system. The mechanical model is assumed as the lumped - parameter model (discrete model), this is the typical technique used for studying the dynamics of gears. The physical model of specific component, for example, gear mesh couple, rolling element bearing is developed are separately to analysis the dynamic of gearbox parts in advance. The entire model that combine with the dynamics of gears, shafts, and bearings is simulated the behavior of mechanical gearbox

\subsection{Dynamic Model of Gears}

There are number of models that used for studying the dynamic of gear mesh. Based on these objectives, gear dynamics models were classified into five groups. The simple dynamic factor model is the earliest model that studied that gear dynamics load. Models with tooth compliance is considered tooth stiffness as the only potential energy storing element in the system, in this model the flexibility of shafts, bearing is neglected. The model for gear dynamics includes the tooth compliance and the flexibility of gearbox components, such as, shafts, bearings etc. Models for geared rotor dynamics study transverse vibrations of gear carrying shafts as well as the lateral component. Models for torsional vibrations consider gears as rigid body that mounted on flexible shafts, and the flexibility at the gear mesh is neglected [9].

In general, gear couple are considered as rigid bodies that the vibration is similar to mass (m) - damper (k) spring (c) - system. The vibration signal is described as the vibration parameters, for example, the displacement, the velocity, and the acceleration in the coordinated system. It is also called multi-DOF system (degree of freedom) or an $\mathrm{N}-\mathrm{DOF}$ system, where $\mathrm{N}$ is the number of coordinates required. The simple coordinated system of the gear mesh couple consists of six degree of freedom, in which each gear has one rotation and two translations (Fig. 1) [8].

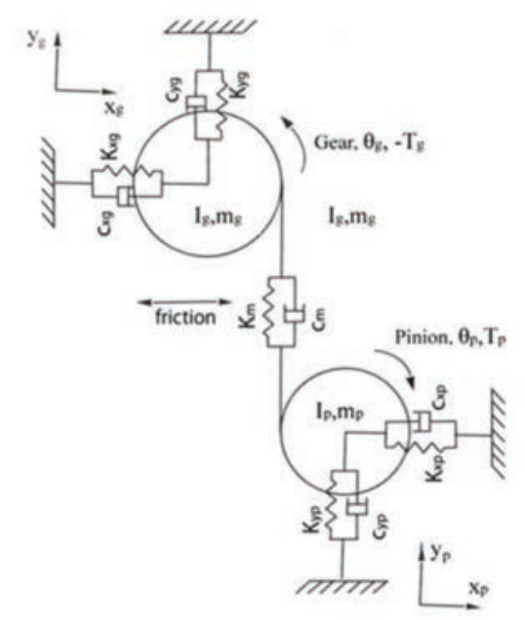

Fig. 1. Dynamic model of gear system with six DOF [8].

The equations of motion for this model can be expressed as follows. The equation of motion in the ' $\mathrm{x}$ ' direction for the pinion and gear [8]:

$$
\begin{aligned}
& m_{p} \ddot{x}_{p}=-K_{x p} x_{p}-C_{x p} \ddot{x}_{p}+F_{p}, \\
& m_{g} \ddot{x}_{g}=-K_{x g} x_{g}-C_{x g} \ddot{x}_{g}+F_{g},
\end{aligned}
$$


The equation of motion in the ' $y$ ' direction for the pinion and gear [8]:

$$
\begin{aligned}
& m_{p} \ddot{y}_{p}=-K_{y p} y_{p}-C_{y p} \ddot{y}_{p}-N, \\
& m_{g} \ddot{y}_{g}=-K_{y g} y_{g}-C_{y g} \ddot{y}_{g}+N,
\end{aligned}
$$

The equation of motion in the ' $\theta$ ' direction for the pinion and gear [8]:

$$
\begin{gathered}
I_{p} \ddot{\theta}_{p}=r_{p} N+T_{p}+M_{p}, \\
I_{g} \ddot{\theta}_{g}=-r_{g} N-T_{g}+M_{g},
\end{gathered}
$$

where: $m_{p}, m_{g}$ - mass of the pinion/gear; $I_{p}, I_{g}$ - mass moment of inertia of the pinion/gear; $K_{x p}, K_{y p}$ - radial stiffness in the $\mathrm{x} / \mathrm{y}$ directions of the pinion; $K_{x g}, K_{y g}$ - radial stiffness in the $\mathrm{x} / \mathrm{y}$ directions of the gear; $C_{x p}, C_{y p}$ - radial damping in the $\mathrm{x} / \mathrm{y}$ directions of the pinion; $C_{x g}, C_{y g}$-radial damping in the $\mathrm{x} / \mathrm{y}$ directions of the gear; $K_{m}$ - equivalent mesh stiffness; $C_{m}$ - mesh damping coefficient; $T_{p}, T_{g}$ - torque applied on the pinion/gear; $r_{p} / r_{g}$-radius of pinion/gear; $F_{p}, F_{g}$ - friction forces for pinion/gear; $N$ - equivalent tangential force.

\subsection{Dynamic Model of Rolling Element Bearings}

Over the past decades, there are number of studies about the dynamic model of rolling element bearing. The simplest bearing model is described as two degree of freedom system, which provides the relation between load and deflection, while the mass and the inertia of rolling elements are neglected. The two DOF are related on inner race (shaft) and the overall contact force summarized of rolling elements effects on the shaft. In this model, stiffness of rolling elements is assumed as non-linear, and it is time-varying in nature as the positions of the rolling elements that determine the overall contact force. The contact force among elements based on the Hertzian theory [10]. The 2-DOF model was developed to a bearing-pedestal model with 4-DOF. The slippage in the rolling elements results from the variation of the load angle. The mass unbalance influence on the rotor and the localized faults on inner race and outer race are manifested [11].

The new bearing-pedestal model has been adopted for studying the dynamics of rolling element bearings with an extra DOF that related to the small sprung mass resulted from typical high frequency (Fig. 2). The elastohydrodynamic lubricant (EHL) does not effect on the model, because of excessive computational demands in analysis cause their effect are integrated in the model.

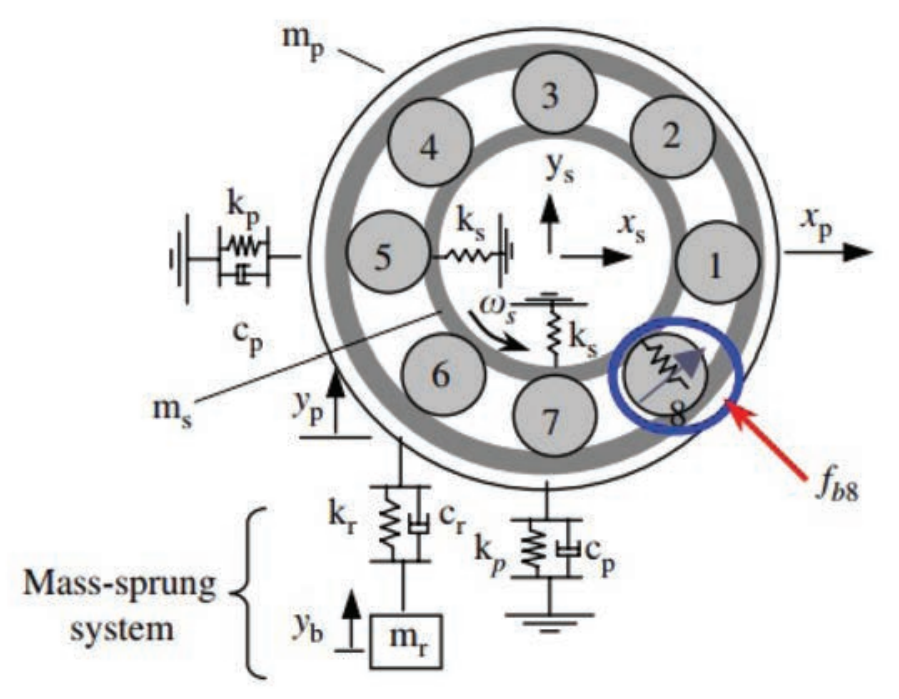

Fig. 2. Dynamic model of bearing system with five DOF [10].

Equations of motion of this model can be expressed [10]:

$$
\begin{aligned}
& m_{s} \ddot{x}_{s}+k_{s}\left(x_{s}\right)+f_{x}\left(\left(x_{s}-x_{p}\right), \omega_{s}, d t\right)=0, \\
& m_{s} \ddot{y}_{s}+k_{s}\left(x_{s}\right)+f_{y}\left(\left(y_{s}-y_{p}\right), \omega_{s}, d t\right)=0,
\end{aligned}
$$




$$
\begin{gathered}
m_{p} \ddot{x_{p}}+c_{p} \dot{x_{p}}+k_{p} x_{p}-f_{x}\left(\left(x_{s}-x_{p}\right), \omega_{s}, d t\right)=0, \\
m_{p} \ddot{y_{p}}+\left(c_{p}+c_{r}\right) \dot{y_{p}}+\left(k_{p}+k_{r}\right) y_{p}-k_{r}-c_{r} \dot{y}_{b}-f_{y}\left(\left(y_{s}-y_{p}\right), \omega_{s}, d t\right)=0,
\end{gathered}
$$

where: $x_{s}, y_{s}$ - shaft/inner race DOF; $x_{p}, y_{p}$ - pedestal/outer race DOF; $y_{b}$ - measured vibration response; $k_{p}$ - pedestal stiffness; $k_{s}$ - shaft stiffness; $k_{r}$ - stiffness of sprung system; $c_{p}$ - damping in pedestal; $c_{r}$ - damping in sprung system; $m_{s}$ mass of shaft/inner race; $m_{p}$ - mass of pedestal; $m_{r}$ - mass of resonance changer; $\omega_{s}$ - shaft rotational speed; $f_{b 8}$ - race way contact force for element 8 .

In these equations, the contact force in $\mathrm{x}, \mathrm{y}$ direction $\left(f_{x}, f_{y}\right)$ is calculated based on Hertzian theory. The overall defection combines three reflection: the modelling of pedestal, the possibility of a localized faults in one of the races, and the slippage in the rolling elements. The deflection of rolling element bearing can be expressed as [10]:

$$
\delta_{i}=\left(x_{s}-x_{p}\right) \cos \phi_{j}+\left(y_{s}-y_{p}\right) \sin \phi_{j}-c-\beta_{j} C_{d},
$$

where: - contact deformation (under compress); - the displacement relation of inner race to outer race in ' $x$ ' and ' $y$ ' direction, - the angular position; $c$ - clearance; $j$ - rolling element $\mathrm{j} ; \beta_{j}$ - fault switch; $C_{d}-$ fault depth.

The contact force can be calculated using Hertzian theory [10]:

$$
f=k_{b} \delta^{n}
$$

From the equation (13), the contact force can be written in ' $\mathrm{x}$ ', and ' $y$ ' direction as follow [10]:

$$
\left\{\begin{array}{l}
f_{x}=k_{b} \sum_{j=1}^{n_{b}} \gamma_{j} \delta_{j}^{n} \cos \phi_{j}, \\
f_{y}=k_{b} \sum_{j=1}^{n_{b}} \gamma_{j} \delta_{j}^{n} \cos \phi_{j},
\end{array}\right.
$$

where: $f$ - contact force; $k_{b}$ - load deflection factor; $n$ - exponent $(n=1.5$ for ball bearing, and $n=1.1$ for roller bearing); $f_{x}, f_{y}$ - contact force in ' $\mathrm{x}$ ' and ' $\mathrm{y}$ ' direction; $n_{b}$ - number of balls (rollers) in bearing; - switch function.

The localized fault is indicated based on the width and the depth of the fault. The localized fault can be estimated by the loss of contact when the rolling element passes over a fault depth $\left(C_{d}\right)$ at a define angular position () over an angular distance () (Fig. 3). The fault switch $\beta_{j}$ is used to calculated the fault in the inner race and outer race [10].
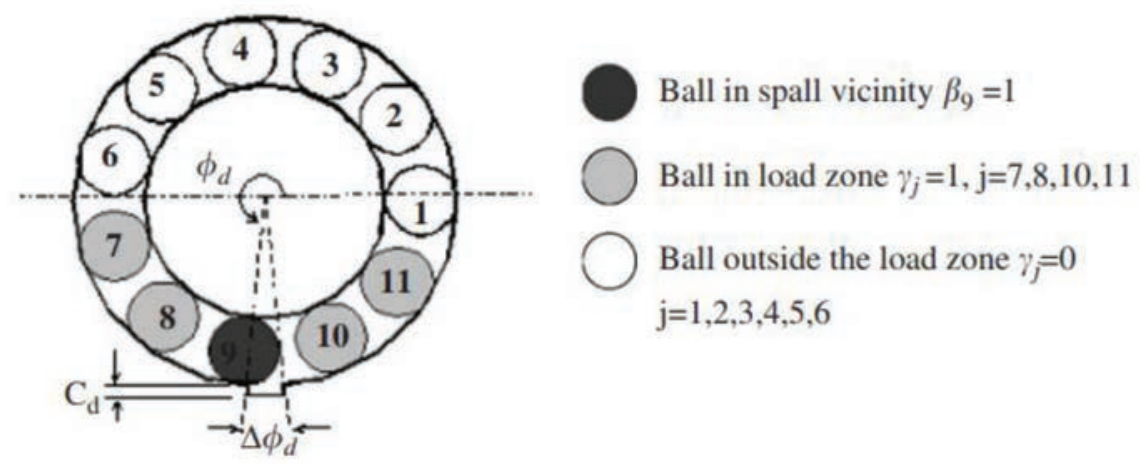

Fig. 3. Localized fault on the outer race [10]

$$
\beta_{i}= \begin{cases}1, \text { if } \phi_{d}<\phi_{j}<\phi_{d}+\Delta \phi_{d} \\ 0 & \text { otherwise }\end{cases}
$$

The location fault on the outer race is fixed in the load zone, whereas the inner race fault rotates at the shaft speed.

$$
\phi_{d}=\omega_{s} t+\phi_{d 0}
$$

where: - angular position; - angular distance; - ball spin frequency; - initial staring location of the spall.

Majority components of bearing consists of four parts: the inner race, the outer race, the cage, and rolling element bearings (ball or roller). The deterioration of each part generates the different characteristic in the frequency spectra. Following equation are used to determine bearing defect frequencies [5]:

Ball pass frequency outer: 


$$
B P F O=\frac{n}{2} f_{r}\left(1-\frac{B D}{P D} \cos \beta\right)
$$

ball pass frequency inner:

$$
B P F I=\frac{n}{2} f_{r}\left(1+\frac{B D}{P D} \cos \beta\right),
$$

ball spin frequency:

$$
B S F=\frac{P D}{2 B D} f_{r}\left(1-\left(\frac{B D}{P D} \cos \beta\right)^{2}\right)
$$

fundamental train frequency (cage failing frequency):

$$
F T F=\frac{1}{2} f_{r}\left(1-\frac{B D}{P D} \cos \beta\right),
$$

where: $n$ - the number of bearing balls or rollers; $f_{r}$ - frequency given by the relative revolution (speed) of the inner and the outer ring; $D P$ - the diameter of bearing ball or roller; $P D$ - pitch diameter; - contact angle; $D$ - outer diameter; $d$ - inner diameter.

\section{Simulation of Gearbox Model}

The gearbox is simulated based on the multi-body dynamics solution. This is an advance computational method for studying dynamics properties of mechanical system, for example, how loads and contact forces are distributed throughout the system.

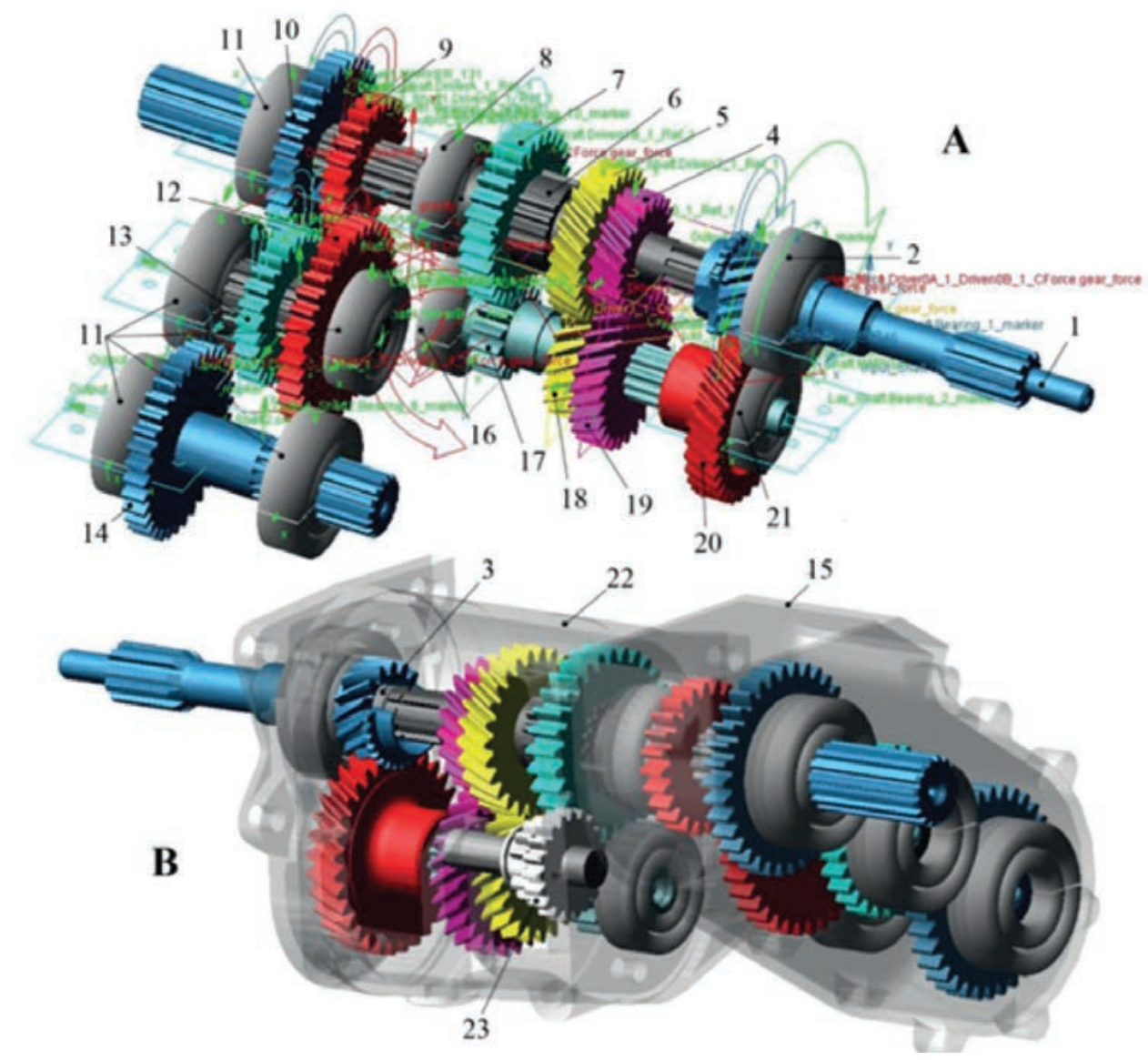

Fig. 4. Multi-body dynamic model of mechanical gearbox [12]. A. Model with all constraints; B. Model with all cases. 1. Input shaft with constant mesh drive gear; 2. Single row deep groove ball bearing SKF 6208; 3 . Roller bearing SKF NU 2204 between the input shaft (1) and the output shaft (6); 4. 3rd speed driven gear; 5. 2nd speed driven gear; 6. Output shaft of gearbox; 7. 1st speed driven gear; 8. Double row angular contact ball bearing SKF 3207BN; 9. 
Rear axle and underdrive engaging gear; 10. Rear axle drive shaft with gear; 11. Single row deep groove ball bearing SKF 6307; 12. Layshaft of transfer box with idle gear; 13. Front axle drive gear; 14. Front axle drive shaft with gear; 15. Transfer gearbox case; 16. Single row deep groove ball bearing SKF 6306; 17. Layshaft (or countershaft) with 1st speed drive gear; 18. 2nd speed drive gear; 19. 3rd speed driver gear; 20. Constant mesh driven gear; 21.Single row deep groove ball bearing SKF 6305; 22. Gearbox case; 23. Reverse gears.Fig. 4. Multi-body dynamic model of mechanical gearbox [12].

Table 1.

Parameters of gears

\begin{tabular}{|c|c|c|c|c|c|c|}
\hline \multirow{2}{*}{ Description } & Item & $\begin{array}{c}\text { Modul } \\
(\mathrm{mm})\end{array}$ & $\begin{array}{c}\text { Face } \\
\text { width } \\
(\mathrm{mm})\end{array}$ & Type & $\begin{array}{c}\text { Helical } \\
\left.\text { Angle }{ }^{\circ}\right)\end{array}$ & Tooth number \\
\hline \multirow{3}{*}{ Constant gear mesh } & Pinion & 3 & 20 & Helical & 28.85 & $\mathrm{Z}_{0 \mathrm{R}}=15$ \\
\cline { 2 - 7 } & Gear & 3 & 20 & Helical & 28.85 & $\mathrm{Z}_{0 \mathrm{~N}}=32$ \\
\hline \multirow{2}{*}{$1^{\text {st }}$ speed } & Pinion & 3.5 & 20 & Spur & & $\mathrm{Z}_{1 \mathrm{R}}=15$ \\
\cline { 2 - 7 } & Gear & 3.5 & 20 & Spur & & $\mathrm{Z}_{1 \mathrm{~N}}=29$ \\
\hline \multirow{2}{*}{$2^{\text {nd }}$ speed } & Pinion & 3 & 20 & Helical & 28.85 & $\mathrm{Z}_{2 \mathrm{R}}=21$ \\
\cline { 2 - 7 } & Gear & 3 & 20 & Helical & 28.85 & $\mathrm{Z}_{2 \mathrm{~N}}=26$ \\
\hline \multirow{2}{*}{$3^{\text {rd }}$ speed } & Pinion & 3 & 20 & Helical & 28.85 & $\mathrm{Z}_{3 \mathrm{R}}=27$ \\
\cline { 2 - 7 } & Gear & 3 & 20 & Helical & 28.85 & $\mathrm{Z}_{3 \mathrm{~N}}=20$ \\
\hline \multirow{2}{*}{ Reverse } & Pinion & 3.5 & 15 & Spur & & $\mathrm{Z}_{\mathrm{RR}}=15$ \\
\cline { 2 - 7 } & Gear & 3.5 & 15 & Spur & & $\mathrm{Z}_{\mathrm{RN}}=19$ \\
\hline
\end{tabular}

The gearbox case and shafts are contacted by bearings that helps to transfer rotational speed in gearbox driveline from low to high frequency. The inner race engaged with the shafts, therefore, they have the same frequencies, while, the outer race is considered as the ground when located on the gearbox case. Majority parameters of bearing that equipped in the gearbox are chosen from the SKF manual handbook and manifested on the Table 2 [8]:

Table 2.

Parameter of bearings

\begin{tabular}{|c|c|c|c|c|c|c|c|}
\hline Parameters & Symbol & SKF 6208 & $\begin{array}{c}\text { SKF NU } \\
2204\end{array}$ & $\begin{array}{c}\text { SKF 3207 } \\
\text { NB }\end{array}$ & SKF 6307 & $\begin{array}{c}\text { SKF } \\
6306\end{array}$ & $\begin{array}{c}\text { SKF } \\
6305\end{array}$ \\
\hline & Position & 2 & 3 & 8 & 11 & 16 & 21 \\
\hline Inner diameter & $\mathrm{d}(\mathrm{mm})$ & 40 & 20 & 35 & 35 & 30 & 25 \\
\hline Outer diameter & $\mathrm{D}(\mathrm{mm})$ & 80 & 47 & 72 & 80 & 72 & 62 \\
\hline Pitch circle & $\mathrm{PD}(\mathrm{mm})$ & 59.9948 & 33.4772 & 53.4924 & 57.4802 & 51.9938 & 43.4848 \\
\hline Diameter of rolling element & $\mathrm{BD}(\mathrm{mm})$ & 11.8872 & 6.477 & 10.3124 & 13.4874 & 11.8872 & 11.0998 \\
\hline Number of rolling elements & $\mathrm{n}$ & 9 & 11 & 14 & 8 & 8 & 7 \\
\hline Contact angle & $\beta(0)$ & 0 & 0 & 30 & 0 & 0 & 0 \\
\hline
\end{tabular}

For modeling the localized of bearing, the deep groove ball bearing SKF that located in the input shaft are chosen for investigated (see Fig. 5). The bearing comprises of the outer race, the inner race, the cage, and nine balls. The outer race connects with ground by the fixed joint, while, two revolute joints are used to connected the inner race with input shaft and the cage with ground. Contact forces are created to connect nine balls with the inner race, the outer race, and the cage. The bearing dynamic model are simulated with 55 DOF. The localized fault is created on the inner race with the width $w=4 \mathrm{~mm}$ and the depth $d=2 \mathrm{~mm}$, in order to investigate an increase of bearing defect frequencies (Fig. 7). 


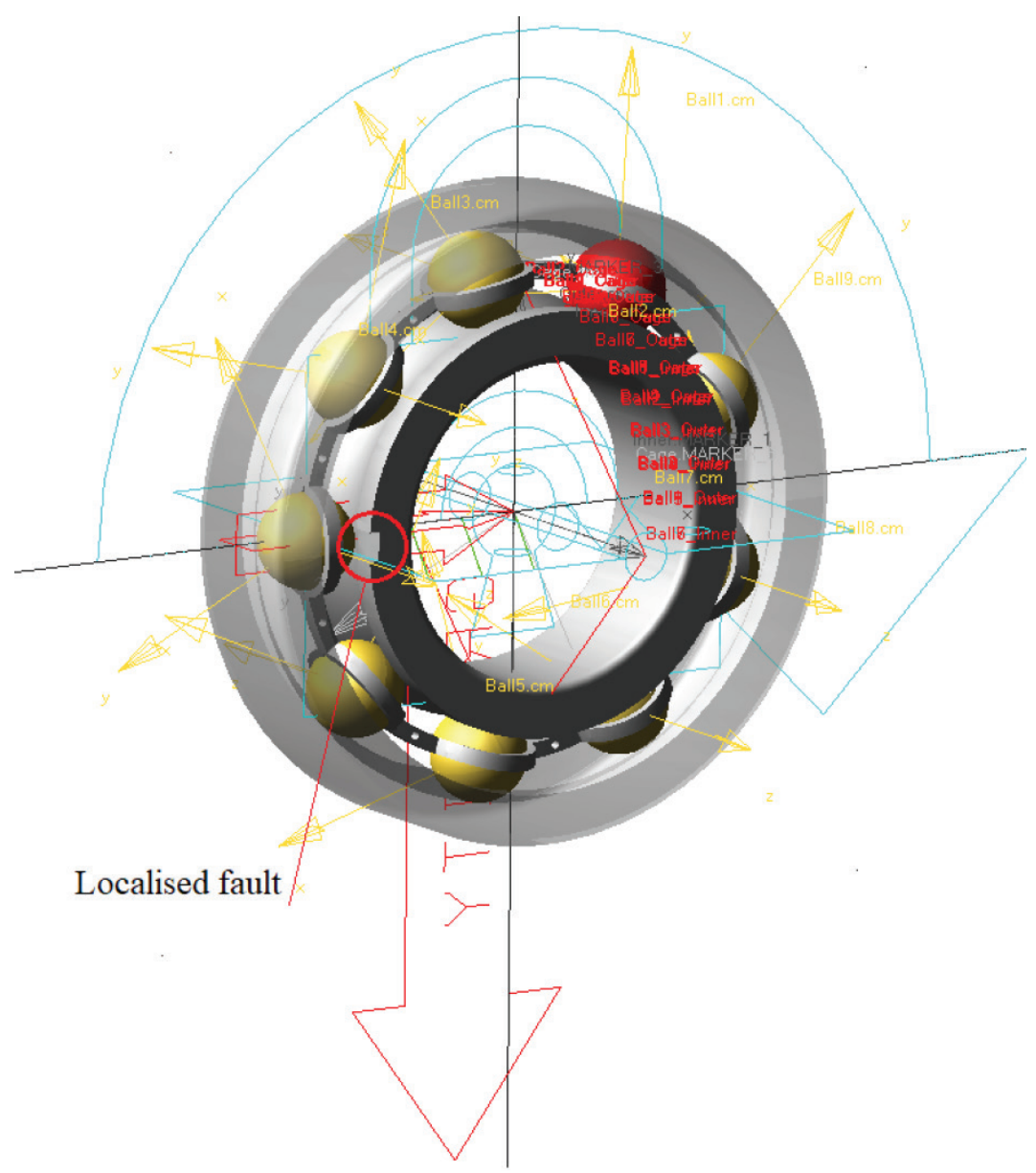

Fig. 5. Multi-body dynamic model of deep groove ball bearing with localized faults on the input race.

Contact forces and geometrical deformations based on the Hertzian contact theory are calculated by algorithms method. The Adams IMPACT method is used for simulating the contact force in mechanical system. The material of bearing SKF 6208 is made from the steel, therefore, the necessary parameters of contact forces for computing are stiffness $\mathrm{k}=100000 \mathrm{~N} / \mathrm{mm}$, force exponent $\mathrm{e}=1.5$, damping $\mathrm{c}=50 \mathrm{Ns} / \mathrm{mm}$, and penetration depth $d=0.1$. The friction force is considered as the Coulomb friction, where static coefficient $\mu$ us $=0.3$, dynamic coefficient $\mu \_$us $=0.25$, stiction transition velocity $v_{-} \mathrm{s}=0.1$ and friction transition velocity $v_{-} \mathrm{d}=10$ [12]. Vibration parameters, for example, displacement, velocity, and acceleration are considered as nonlinear equations and solved by INTEGRATOR in Adams Solver. The initial condition is set up with the input rotational velocity as $2000 \mathrm{rpm}$ $(33.33 \mathrm{~Hz})$. The step function is used to simulate the rotational velocity of the input shaft. The dynamic model is simulated in two case: the one is the health condition while another is the localized fault on the inner race. The measure function is used to measure the acceleration in the Rotational Joint between inner race and input shaft.

After investigations, results are analyzed in the post-processing environment. The Fig. 6 shows the translational acceleration of peak - to - peak value in ' $y$ ' direction in the time domain. The internal time is chosen from $0.5 \mathrm{~s}$ to $1 \mathrm{~s}$, where, the vibration manifests the harmonic after $\mathrm{t}=0.095 \mathrm{~s}$. When the ball passes the crack on the inner race, the vibration roars up dramatically, after that coming back the periodic. These increase peaks are related to the localized faults of bearing. 


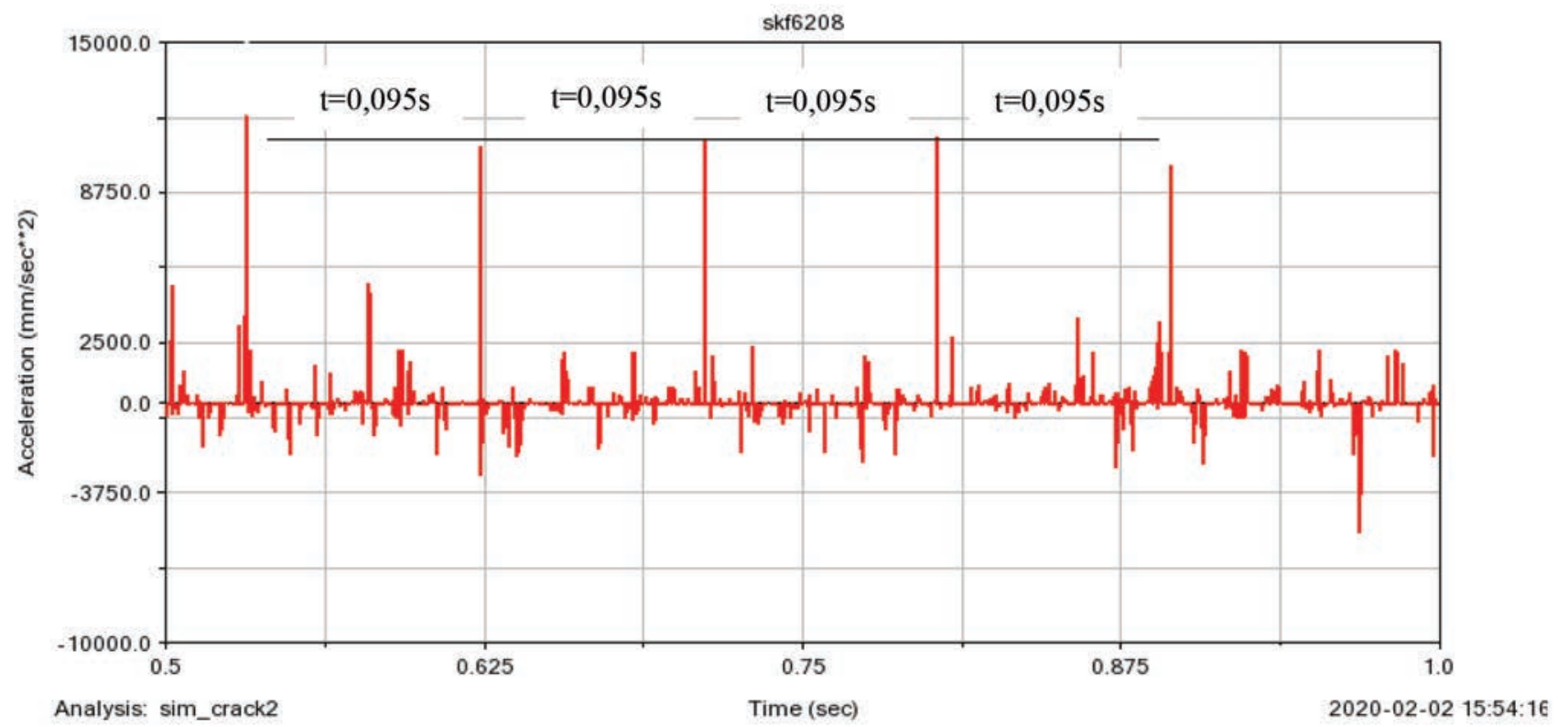

Fig. 6. Waveform of localized fault.

The localized fault induces the increase of overall vibration signal and the growth of the peak. However, the signal does not show the characteristic of the bearing fault. To overcome this disadvantage of this technique, the Fast Fourier Transform function is used to transform the vibration signal to frequency domain (Fig. 7). The spectrum in the upper shows the translational acceleration of "health" bearing, while, the lower shows the signal when the spall occurs on the outer ring. When the spall fault occurs, the overall vibration signal increases. The first peak is related to the $1 \mathrm{X}$ frequency of the input rotational velocity. The bearing defect frequency inner of the bearing SKF 6208 is calculated BPFI $=159.98 \mathrm{~Hz}$. The defect frequency of inner race when the fault occurs in the simulation process is about BPFI $=169.25 \mathrm{~Hz}$. When the spall occurs on the outer race, the BPFI frequency increases in the lower picture.
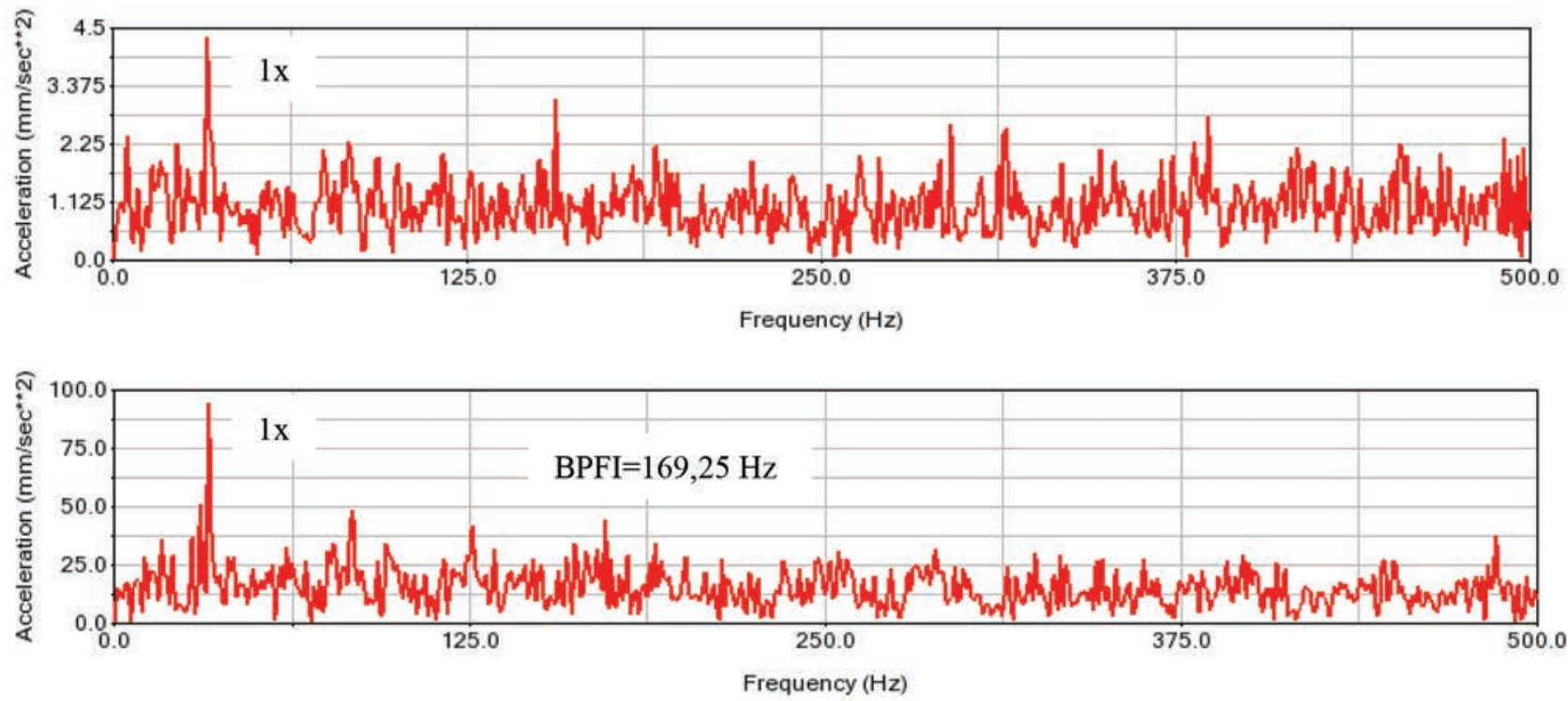

Fig. 7. Spectrum of localized fault: heathy bearing (upper) and localized fault (lower).

\section{Conclusions}

In this paper, the dynamic model of gearbox based on the multi-body dynamics solution is presented. The model are combined gears and bearings to study the interaction induced by the presence of the localized fault. The bearing is considered as lump mass parameter system with 55 DOF modeling from bearing elements, such as, the inner race, the outer race, the cage, and nine balls. The localized fault is created on the inner race for investigate the 
increase of vibration signal when the fault occurs. Mechanical contact forces base on the Hertzian contact theory and calculates by Impact function in MSC Adams solver. Results are analyzed the translational acceleration in the time domain and frequency domain. The waveform shows the harmonic and an increase when the ball passes over the spall on the inner race, while, the spectrum show the growth of ball pass frequency inner. The model is further developed to simulation the different localized faults and to analysis the variation of lump parameters on dynamic of gearbox model.

\section{Acknowledgements}

Presented work has been prepared with the support of the Ministry of Defence of the Czech Republic, Partial Project for Institutional Development and Specific Research, Department of Combat and Special Vehicles, University of Defence in Brno.

\section{References}

1. Stamm J.A. Machinery diagnostics via mechanical vibration analysis using spectral Analysis techniques. Naval postgraduate school Monterey CA, 1988

2. Blodt, M., Granjon, P., Raison, B., Rostaing, G. Models for bearing damage detection in induction motors using stator current monitoring. IEEE transactions on industrial electronics, 55(4), 2002, p. 1813-1822.

3. Sheng, S. Gearbox typical failure modes, detection, and mitigation methods (Presentation) (No. NREL/PR-500060982). National Renewable Energy Laboratory (NREL), Golden, CO, 2014.

4. Tandon N., Choudhury A. An analytical model for the prediction of the vibration response of rolling element bearings due to a localized defect. Journal of sound and vibration 205.3, 1997, p.275-292.

5. Furch J., Glos J., Nguyen TT. Identification of the technical condition of roller bearings by means of vibrodiagnostics and tribodiagnostics. Transactions of FAMENA, 41(3), 2017, p.99-113.

6. Wagner C., Krinner A., Thümmel T., Rixen D. Full dynamic ball bearing model with elastic outer ring for high speed applications. Lubricants, 5(2), 2017, 17p.

7. Sopanen J., Mikkola A. Dynamic model of a deep-groove ball bearing including localized and distributed defects. Part 1: Theory. Proceedings of the Institution of Mechanical Engineers, Part K: Journal of Multi-body Dynamics, 217(3), 2003, p.201-211.

8. Tran C.V., Furch J. Multi-body dynamics model analysis of failures in passenger off-road military vehicle gearbox. Transport Means - Proceedings of the International Conference, 2019, p.141-147.

9. Özgüven, H.N., Houser, D.R. Mathematical models used in gear dynamics a review. Journal of sound and vibration, 121(3), 1988, p. 383-411.

10. Sawalhi, N., Randall, R.B. Simulating gear and bearing interactions in the presence of faults: Part I. The combined gear bearing dynamic model and the simulation of localised bearing faults. Mechanical Systems and Signal Processing, 22(8), 2008, p. 1924-1951.

11. Feng, N.S., Hahn, E.J., Randall, R.B. Using transient analysis software to simulate vibration signals due to rolling element bearing defects. In Applied Mechanics: Progress and Applications, 2002, p. 689-694.

12. Tran, C.V., Furch, J., Cu, X.P. Simulation of Multi-body Dynamic Model in Mechanical Vehicle Gearbox. In 2019 International Conference on Military Technologies (ICMT), 2019, p. 1-5. IEEE. 